\title{
Evolution of Escherichia coli to Macrophage Cell Line
}

Migla Miskinyte and Isabel Gordo*

Evolutionary Biology Group, Instituto Gulbenkian de Ciência, Oeiras, Portugal

*For correspondence: igordo@igc.gulbenkian.pt

[Abstract] The genomes of species of Escherichia coli (E. coli) show an extraordinary amount of diversity, which include commensal strains and strains belonging to different pathovars. Many strains of E. coli, which can cause mild or severe pathologies in humans, have a commensal ancestor. Understanding the evolutionary changes that can lead to a transition from commensal to pathogen is an important task, which requires integration of different methodologies. One method is experimental evolution of bacteria, in controlled environments, that mimic some of the selective pressures, likely to be important during the transition to pathogenesis. The success of such a transition will depend, at least partially, on ability of $E$. coli to adapt to the presence of cells of the immune system. Here, we describe a protocol for performing experimental evolution of a commensal strain of $E$. coli, a derivative of the well studied $\mathrm{K} 12$, under the constant selective pressure imposed by cells of the innate immune system, specifically RAW 264.7 murine macrophage cell line.

\section{Materials and Reagents}

1. RAW 264.7 murine macrophage cell line (MФ) (Sigma-Aldrich, catalog number: 91062702)

2. E. coli strains, marked with constitutive expression of yellow (YFP) and cyan (CFP) fluorescent proteins (e. g. E. coli- MC4100, galK::CFP/YFP, Amp ${ }^{R}$ Strep $^{R}$ )

3. RPMI media1640 (Life Technologies, Gibco ${ }^{\circledR}$, catalog number: 11875-093)

4. 2-mercaptoethanol solution (Life Technologies, Invitrogen ${ }^{\mathrm{TM}}$, catalog number: 31350-010)

5. $1 \mathrm{M}$ Hepes buffer (Life Technologies, Invitrogen ${ }^{\mathrm{TM}}$, catalog number: 15630-056)

6. $100 \mathrm{mM}$ sodium pyruvate (Life Technologies, Invitrogen ${ }^{\mathrm{TM}}$, catalog number: 11360-039)

7. Heat-inactivated Fetal Bovine Serum (FBS) (Life Technologies, Gibco ${ }^{\circledR}$, catalog number: 10500-064)

8. GlutaMAX (100X) (Life Technologies, Gibco ${ }^{\circledR}$, catalog number: 35050-038)

9. $10,000 \mathrm{U} / \mathrm{ml}$ penicillin/streptomycin (Life Technologies, Gibco ${ }^{\circledR}$, catalog number: 15140122)

10. Streptomycin sulfate salt (Sigma-Aldrich, catalog number: S9137)

11. $50 \mathrm{mg} / \mathrm{ml}$ gentamycin solution (Sigma-Aldrich, catalog number: G1397) 
12. $1 x$ phosphate-buffered saline (PBS)

13. Trypan Blue solution (Sigma-Aldrich, catalog number: T8154)

14. CpG-ODN -1826 (5'-TCCATGACGTTCCTGACGTT-3') (Sigma-Aldrich)

15. RPMI-complete media (see Recipes)

16. RPMI-Strep media (see Recipes)

\section{Equipment}

1. $\mathrm{CO}_{2}$ incubators

2. Microscope

3. Luria-Bertani (LB) agar plates (Panreac Life-sciences, catalog number: 596661.1210)

4. Centrifuge (Sigma-Aldrich, model: 4K15 with a rotor 11150)

5. Neubauer cell counting chamber (VWR International, catalog number: 631-1114)

6. Air flow chamber

7. 12-well microtiter plates (Costar, catalog number: 3513)

8. Cell culture flasks ( $25 \mathrm{~cm}^{2}$ and $75 \mathrm{~cm}^{2}$ growth area) (Corning, catalog numbers: 430639 and 430641)

9. $15 \mathrm{ml}$ Falcon tubes

10. Cell scrapers $(16 \mathrm{~cm}$ and $25 \mathrm{~cm}$ ) (SARSTEDT AG, catalog numbers: 83.1832 and 83.1830)

11. $2 \mu \mathrm{m}$ size beads (Sphero AccuCount Blank Particles) (Spherotech, catalog number: ACBP-20-10)

12. LSR Fortessa Flow cytometer

\section{Procedure}

1. Grow $M \Phi$ in two $75 \mathrm{~cm}^{2}$ culture flasks (20 ml total volume) in RPMI- complete media until 80\% (flask A) and 25\% (flask B) confluency (Note 1).

Condition: The cell cultures are maintained in an incubator with $5 \% \mathrm{CO}_{2}$ and $37{ }^{\circ} \mathrm{C}$, including incubation steps.

Day 1

2. Remove old media, add fresh media (same volume) and detach $M \Phi$ with a $25 \mathrm{~cm}$ cell scraper from the flask $A$.

3. Carefully pipette culture up and down until pellet is dissolved.

4. Leave $5 \mathrm{ml}$ of the cell suspension in the flask $\mathrm{A}$ and add $15 \mathrm{ml}$ of RPMI-complete media.

5. Centrifuge remaining $15 \mathrm{ml}$ of $\mathrm{M} \Phi$ cell suspension in two $15 \mathrm{ml}$ Falcon tubes at 1,200 rpm for $5 \mathrm{~min}$ (Note 2). 
6. Remove supernatant and re-suspend pellet in the same volume of RPMI-Strep media (7.5 $\mathrm{ml}$ for each falcon tube) (Note 3).

7. Count $M \Phi$ in the Neubauer cell counter with Trypan blue viability dye (use $10 \mu \mathrm{l}$ of cell suspension with $10 \mu \mathrm{l}$ of dye) and use approximately 0.7-1.3 $\times 10^{6} \mathrm{cells} / \mathrm{ml}$ for activation. Allow the dye to stain for approximately 5 to $15 \mathrm{~min}$. If cells are exposed to extended period of time to this dye, viable cells, as well as nonviable cells, may begin to uptake dye.

8. Transfer this amount of cells into a $25 \mathrm{~cm}^{2}$ flask ( $8 \mathrm{ml}$ total volume) and activate them with CpG-ODN at a final concentration of $2 \mu \mathrm{g} / \mu \mathrm{l}$ for $24 \mathrm{~h}$ (Note 4).

9. Grow E. coli - CFP (or YFP) bacterial population from the frozen stock in RPMI-Strep media in the 12-well plates ( $3 \mathrm{ml}$ of the total volume for each well) for $24 \mathrm{~h}$ in the same conditions as the cell cultures $\left(\mathrm{CO}_{2}\right.$ incubator at $37^{\circ} \mathrm{C}$ and $\left.5 \% \mathrm{CO}_{2}\right)($ Note 5$)$.

Day 2

10. Repeat steps 2-8 with $M \Phi$ from the flask $B$.

11. Repeat steps 2-3 with activated $M \Phi$ from flask $A$ (use a $16 \mathrm{~cm}$ scraper).

12. Centrifuge $M \Phi$ cell suspension in one $15 \mathrm{ml}$ Falcon tube at 1,000 rpm for $5 \mathrm{~min}$ and resuspend using RPMI-Strep at the same volume.

13. After counting the cells, seed activated $M \Phi$ at $0.8-1.6 \times 10^{6} \mathrm{cells} / \mathrm{ml}$ in 12 -well microtiter plates ( $3 \mathrm{ml}$ of total volume for each well).

14. Allow cells to attach in the $37^{\circ} \mathrm{C}, 5 \% \mathrm{CO}_{2}$ incubator for $2 \mathrm{~h}$.

15. Count numbers of grown bacteria by using $2 \mu \mathrm{m}$ size beads in the Flow cytometer (Note $6)$.

16. Wash activated and attached MФ with RPMI-Strep media (remove old and add new media, same volume).

17. Infect activated $M \Phi$ at the multiplicity of infection (MOI) of 1 to $1\left(10^{6}\right.$ bacteria/ml to $10^{6}$ $\mathrm{M} \Phi / \mathrm{ml})$.

Day 3

18. Repeat steps 2-8 with $M \Phi$ from the flask $A$.

19. Repeat steps 2-3 with activated $M \Phi$ from flask $B$ (use a $16 \mathrm{~cm}$ scraper).

20. Centrifuge $M \Phi$ cell suspension in one $15 \mathrm{ml}$ falcon tube at 1,000 rpm for $5 \mathrm{~min}$ and resuspend using RPMI-Strep at the same volume.

21. After counting the cells, seed activated $M \Phi$ at $0.8-1.6 \times 10^{6} \mathrm{cells} / \mathrm{ml}$ in 12 -well microtiter plates ( $3 \mathrm{ml}$ of total volume for each well) and allow cells to attach in the $37^{\circ} \mathrm{C} 5 \% \mathrm{CO}_{2}$ incubator for $2 \mathrm{~h}$.

22. After $24 \mathrm{~h}$ of infection (12-well infection plate from the Day 2), detach $M \Phi$ with a $16 \mathrm{~cm}$ cell scraper and centrifuge culture at 4,000 rpm for $10 \mathrm{~min}$. This procedure lyses $M \Phi$ and releases intracellular bacteria (Note 7). 
23. Discard the supernatant and resuspend each pellet in $3 \mathrm{ml}$ of PBS.

24. Dilute bacteria in PBS, count their numbers in flow cytometer.

25. Use this bacteria to infect activated $M \Phi$ again (from flask $B$ ) at the multiplicity of infection (MOI) of 1 to $1\left(10^{6}\right.$ bacteria/ml to $\left.10^{6} \mathrm{M \Phi s} / \mathrm{ml}\right)$.

26. Freeze a sample of the bacterial culture every day and keep your stocks ("fossil records") at $-80^{\circ} \mathrm{C}$.

27. Repeat steps from Day 2 and Day 3 to continue with evolution experiment (Note 8).

\section{Notes}

1. To be able to repeat the same protocol every day, maintain MФ always in the two $75 \mathrm{~cm}^{2}$ culture flasks. Use $\mathrm{M \Phi}$ from the flask $A$ for every odd and the flask $B$ for every even day of evolution experiment. To estimate confluency compares the amount of space covered by cells with unoccupied spaces.

(check: http://www.abcam.com/ps/pdf/protocols/cell culture.pdf).

2. If $M \Phi$ culture has many dead (aggregated or detached) cells centrifuge at $800 \mathrm{rpm}$, this way healthy cells will pellet at the bottom of the tube and dead cells will remain mainly in the supernatant.

3. Streptomycin is used to enable the growth of STR resistant E. coli in the media and control for possible contaminations by other bacteria. If you use different antibiotic, test if antibiotic is not toxic for $М \Phi$ cell line.

4. This dilution is necessary because $M \Phi$ will grow in $24 \mathrm{~h}$. We use CpG-ODN-1826, because ODN 1826 is a B-class CpG ODN specific for mouse TLR9 that leads to strong immunostimulatory effects after $24 \mathrm{~h}$ of activation. If you intend to use other cell line (e.g. ODN 2395 is specific for class C human TLR9) choose an appropriate ODN. How to prepare a bacterial stock for evolution experiment:

a. Streak a bacterial culture on LB plate and grow for $24 \mathrm{~h}$ at $37^{\circ} \mathrm{C}$.

b. Isolate and inoculate a single bacterial colony into RPMI-Strep media.

c. After $24 \mathrm{~h}$ of growth, freeze culture in glycerol solution [500 $\mu \mathrm{l}$ of bacterial culture with $500 \mu \mathrm{l}$ of glycerol (30\% stock solution)].

d. Use this stock to start evolution experiment.

5. You can use the following dilution to count in the flow cytometer: $10 \mu \mathrm{l}$ of bacterial culture (diluted 1: 100), $10 \mu \mathrm{l}$ of beads and $180 \mathrm{ml}$ PBS.

6. You can also detach $M \Phi$, by bending a blue $1,000 \mu \mathrm{l}$ pipette tip and using it as a scraper. Remember that for each replicate well you need to use a new sterile scraper. 
7. To perform phenotypic characterization of the evolved E. coli check our other protocol "Fitness Measurements of Evolved Esherichia coll" (Miskinyte and Gordo, 2014) and original paper (Miskinyte et al., 2013).

\section{$\underline{\text { Recipes }}$}

1. RPMI-complete media

500 ml RPMI 1640

$50 \mathrm{ml}$ FBS

$5 \mathrm{ml}$ sodium pyruvate

$5 \mathrm{ml}$ hepes

$5 \mathrm{ml}$ L-glutamax

$0.5 \mathrm{ml}$ 2-mercaptoethanol solution

$0.5 \mathrm{ml}$ gentamycin solution

$5 \mathrm{ml}$ penicillin/streptomycin solution

Stored at $4{ }^{\circ} \mathrm{C}$

2. RPMI-Strep media

$500 \mathrm{ml}$ RPMI 1640

$50 \mathrm{ml}$ FBS

$5 \mathrm{ml}$ sodium pyruvate

$5 \mathrm{ml}$ hepes

$5 \mathrm{ml} \mathrm{L-glutamax}$

$0.5 \mathrm{ml}$ 2-mercaptoethanol solution

$1 \mathrm{ml}$ of $50 \mathrm{mg} / \mathrm{ml}$ streptomycin solution

Stored at $4{ }^{\circ} \mathrm{C}$

\section{Acknowledgments}

This protocol was adapted or modified from Lenski et al. (1991). The research received funding from the European Research Council under the European Community's Seventh Framework Programme (FP7/2007-2013)/ERC grant agreement no 260421 - ECOADAPT. IG acknowledges the salary support of LAO/ITQB \& FCT.

\section{$\underline{\text { References }}$}

1. Lenski, R. E., Rose, M. R., Simpson, S. C. and Tadler, S. C. (1991). Long-term experimental evolution in Escherichia coil. I. Adaptation and divergence during 2,000 generations. American Naturalist 138:1315-1341. 
2. Miskinyte, M. and Gordo, I. (2014). Fitness measurements of Evolved Esherichia coli. Bio-protocol 4(17): e1228.

3. Miskinyte, M., Sousa, A., Ramiro, R. S., de Sousa, J. A., Kotlinowski, J., Caramalho, I., Magalhaes, S., Soares, M. P. and Gordo, I. (2013). The genetic basis of Escherichia coli pathoadaptation to macrophages. PLoS Pathog 9(12): e1003802. 